\title{
An Integrated Multi-Model Decision Support Framework for Evaluating Ecosystem-Based Management Options for Coupled Human-Natural Systems
}

\author{
Robert B. McKane, Allen F. Brookes, Kevin S. Djang, Jonathan J. Halama, \\ Paul B. Pettus, Bradley L. Barnhart, Marc Russell, Kellie B. Vache, \\ and John P. Bolte
}

\begin{abstract}
Simulation models offer a way to achieve a comprehensive understanding of the consequences of alternative community planning scenarios. For example, a community might want to understand how a particular decision-such as expanding an urban growth boundary into lands zoned for agriculture-will result in ecological, economic, and social tradeoffs for various stakeholder groups. This chapter explores the utility of ENVISION, a spatially-explicit decision support framework that integrates various ecological and human systems model "plug-ins" for informing Ecosystem-Based Management (EBM) options. While ENVISION already has a reasonably large tool box of such plug-ins, its usefulness could be further extended to address a wider range of community and ecosystem types. We specifically examine how a suite of existing U.S. Environmental Protection Agency decision support tools (VELMA, HexSim, CORESET, Coral PF and others) could significantly extend ENVISION's plug-in toolbox for coastal ecosystem EBM, inclusive of terrestrial-marine interactions and restoration goals of coastal communities dependent on marine ecosystem services.
\end{abstract}

\footnotetext{
R. B. McKane $(\bowtie) \cdot$ A. F. Brookes · J. J. Halama · P. B. Pettus

U.S. Environmental Protection Agency, Corvallis, OR, USA

e-mail: Mckane.Bob@epa.gov

K. S. Djang

Inoventures LLC, c/o U.S. Environmental Protection Agency, Corvallis, OR, USA

B. L. Barnhart

National Council for Air and Stream Improvement, Inc., Corvallis, OR, USA

M. Russell

US Environmental Protection Agency, Center for Computational Toxicology and Exposure,

Gulf Breeze, FL, USA

K. B. Vache · J. P. Bolte

Oregon State University, Corvallis, OR, USA
} 


\section{Lessons Learned}

- Advances in applications of ENVISION over the past decade-e.g., the Willamette Water 2100 application — represent a major step forward for identifying EBM solutions to intertwined and seemingly insoluble (aka, wicked) environmentaleconomic-social problems.

- Depending upon the complexity and scope of EBM objectives, applications of ENVISION or similar human-natural systems modeling frameworks can involve substantial effort and cost.

- Costs/benefits of applications of ENVISION or similar tools should be weighed against alternatives, such as applications of stand-alone EBM models, reliance on purely empirical studies, or some combination.

\section{Needs to Advance EBM}

- Develop and apply model plug-ins that extend ENVISION's applicability to coastal ecosystems, particularly for identifying policies and EBM best practices for reducing sources and runoff of terrestrial pollutants to estuarine ecosystems.

\section{Introduction}

Communities invest significant time and resources in planning and want to understand the consequences of decisions they are considering. Those consequences can be complex and far reaching, affecting a wide range of stakeholders having different priorities. One way to attempt to understand the consequences of change is by using models. For example, a community might want to understand how forest harvest will affect a watershed's capacity to provide clean drinking water. For this context they might model the hydrology and biogeochemistry of selected areas to estimate how stream flow and nutrient loading may change as a result of logging. But the consequences do not end with flow and nutrients. How, where, and when the logging is done will also affect costs, jobs, revenue, fish and wildlife populations, and recreation inside and outside the harvested areas.

To gain a more comprehensive understanding of the ecological, economic and social consequences of any given land management decision option, the community would ideally use a framework capable of modeling these consequences in an integrated way, since each can directly or indirectly influence the others. Integrated modeling that supports Ecosystem-Based Management (EBM) can be very difficult and time consuming. To simplify the task, communities would benefit from a modeling framework with a tool box of plug-in models that can be tailored to address their specific needs.

Such an EBM framework would need to allow integration of varied plug-in models with a way for the models to share data. Much of the data will be spatial, so the framework must provide a shared GIS platform. In addition, there should be a way to test multiple scenarios and to provide optimization. Finally, there should be a way to provide constraints on what decisions can be made corresponding to a location's laws and policies (e.g., land use laws). 
One such framework is ENVISION, developed primarily at Oregon State University (Bolte and Vache 2010; Santelmann et al. 2012; Spies et al. 2014; Bradley et al. 2016; Villarreal et al. 2017). ENVISION provides all the features listed above and is a mature, publicly available product (http://envision.bioe.orst.edu/Down loads.aspx). Using an extensible array of integrated plug-in models, ENVISION has been used to analyze ecological, economic and social tradeoffs in response to alternative future scenarios for coupled human-natural systems in a variety of locations. Some examples include the Puget Sound region in Washington, the Big Woods drainage in Idaho, and the Willamette River Basin and Tillamook Bay in Oregon. (http://envision.bioe.orst.edu/CaseStudies.aspx).

Goals of this chapter are to provide (1) an overview of ENVISION and an example of a regional-scale application; (2) an example of the process by which an existing spatial model can be integrated with ENVISION as a plug-in; and (3) recommendations for developing additional model plug-ins to further extend ENVISION's capabilities for integrated EBM planning. Our intent is to illustrate a path for integrating various existing EBM models within a well-established decision support framework that community planners and stakeholders can use to explore ecological, economic, and social tradeoffs associated with different decision options.

\section{ENVISION-A Decision Support Tool for Ecosystem-Based Management}

\subsection{ENVISION Overview}

ENVISION is a framework for constructing alternative future scenario applications concerning ecological, economic and social outcomes of interest to communities and regional planners. The framework consists of four main components (http://envision. bioe.orst.edu/About.aspx):

1. A dynamic spatial (GIS) engine for representing polygonal, network, point, and grid-based landscape characterizations.

2. A multi-agent modeling framework for representing values and behaviors of different decision-makers (agents) on the landscape.

3. A rich representation of policies guiding and constraining agent decision-making, and scenarios describing alternative strategies for landscape management.

4. An extensible plug-in architecture for including:

(a) Any number of conformant autonomous process models describing landscape change dynamics;

(b) Any number of "evaluative models" reporting landscape production metrics, typically measured in terms of scarcity along biophysical, ecological, social or economic dimensions; 
(c) Any number of "visualizers" for visual representation of spatial data and inputs.

Figure 1 illustrates how these ENVISION components are integrated and feed back upon each other over time and space.

Other EBM decision support frameworks-notably InVEST and ARIES - share many of these capabilities (see Lewis et al. 2020). ENVISION stands out for its emphasis on the integration of ecological, social and economic models (plug-ins) with a sophisticated agent-based modeling subsystem. It also enables a rich representation of local and regional policies guiding and constraining actions of human decision-makers (agents) in landscape-scale simulations. Agents can be individuals, such as landowners and other citizens; or organizations and institutions, such as governments and businesses.

A main purpose of ENVISION's human-natural systems modeling approach is to facilitate discourse among different decision-makers and enable them to interactively play out and compare consequences of alternative management and regulatory choices.

\subsection{Example Application-ENVISION Willamette}

The ENVISION Willamette Water 2100 project—aka, ENVISION Willamette-is a good example of this framework's capabilities. ENVISION Willamette is a regional human-natural systems application that closely engaged community and regional decision-makers concerned with current and future supplies, usage and management of water resources within the $30,000 \mathrm{~km}^{2}$ Willamette River Basin in the state of Oregon, USA (e.g., Bolte et al. 2011; Jaeger et al. 2017). The Willamette River is the 13th largest river in the USA. The river and its basin support a mosaic of agricultural, timber, recreational resources and several rapidly growing urban centers dependent on surface water supplies.

The ENVISION Willamette project involved a collaborative effort of Oregon State University, the University of Oregon, Portland State University, and the University of California-Santa Barbara. The project team used a structured decision-making approach to set up this ENVISION application (Fig. 2). Through a series of stakeholder engagement workshops, local, state, and federal stakeholders identified pressures and ecosystems services deemed important to their immediate and long-term ecological, economic, and social goals. Models of landscape processes relevant to these goals were then identified and plugged in to ENVISION. Plug-in models included forest ecosystem dynamics, land use change, human population growth, watershed hydrology, and storage of carbon within ecosystems (see next section for plug-in details). Relevant spatial datasets, policies and decision alternatives were then assembled to inform these models and build project scenarios. 


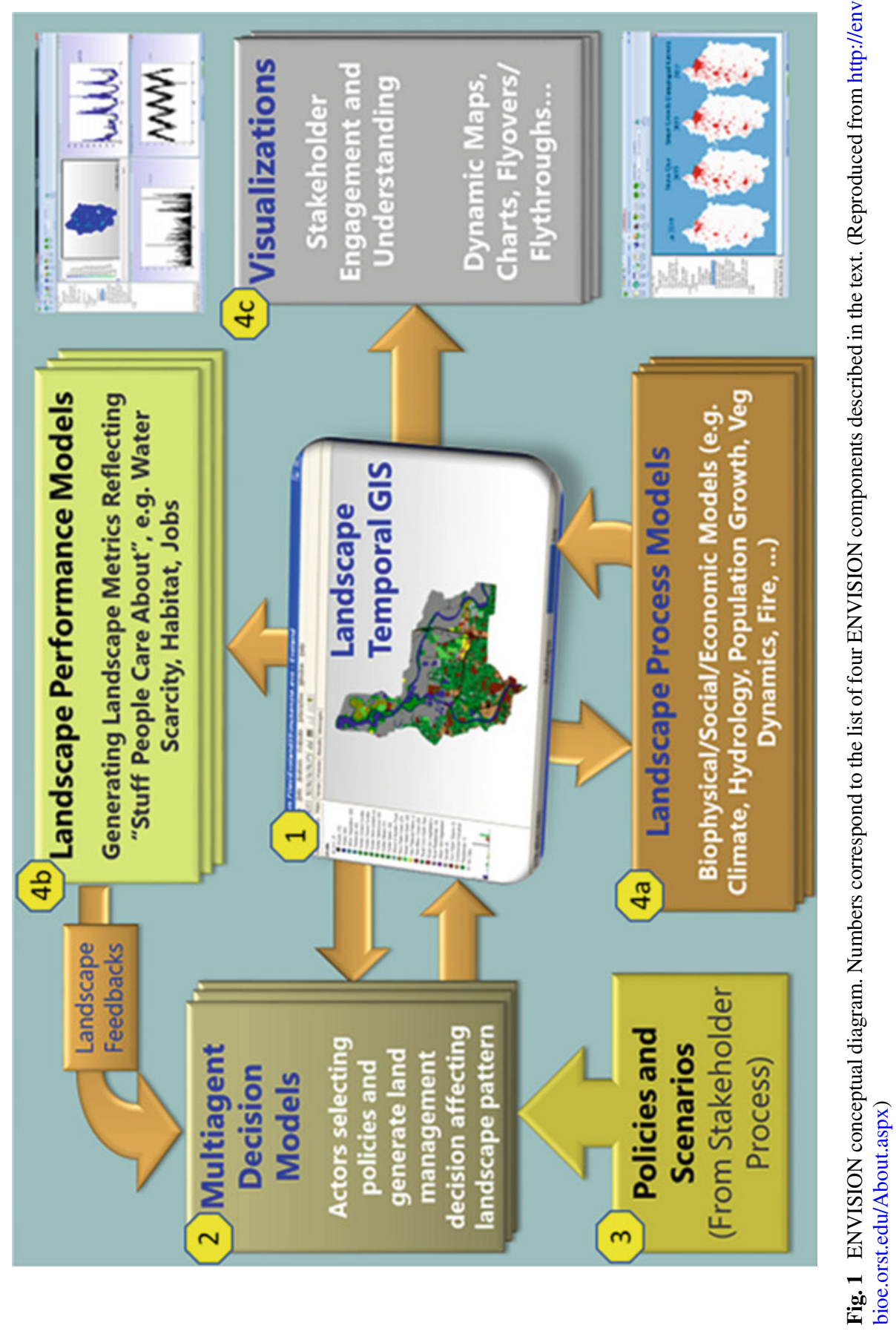




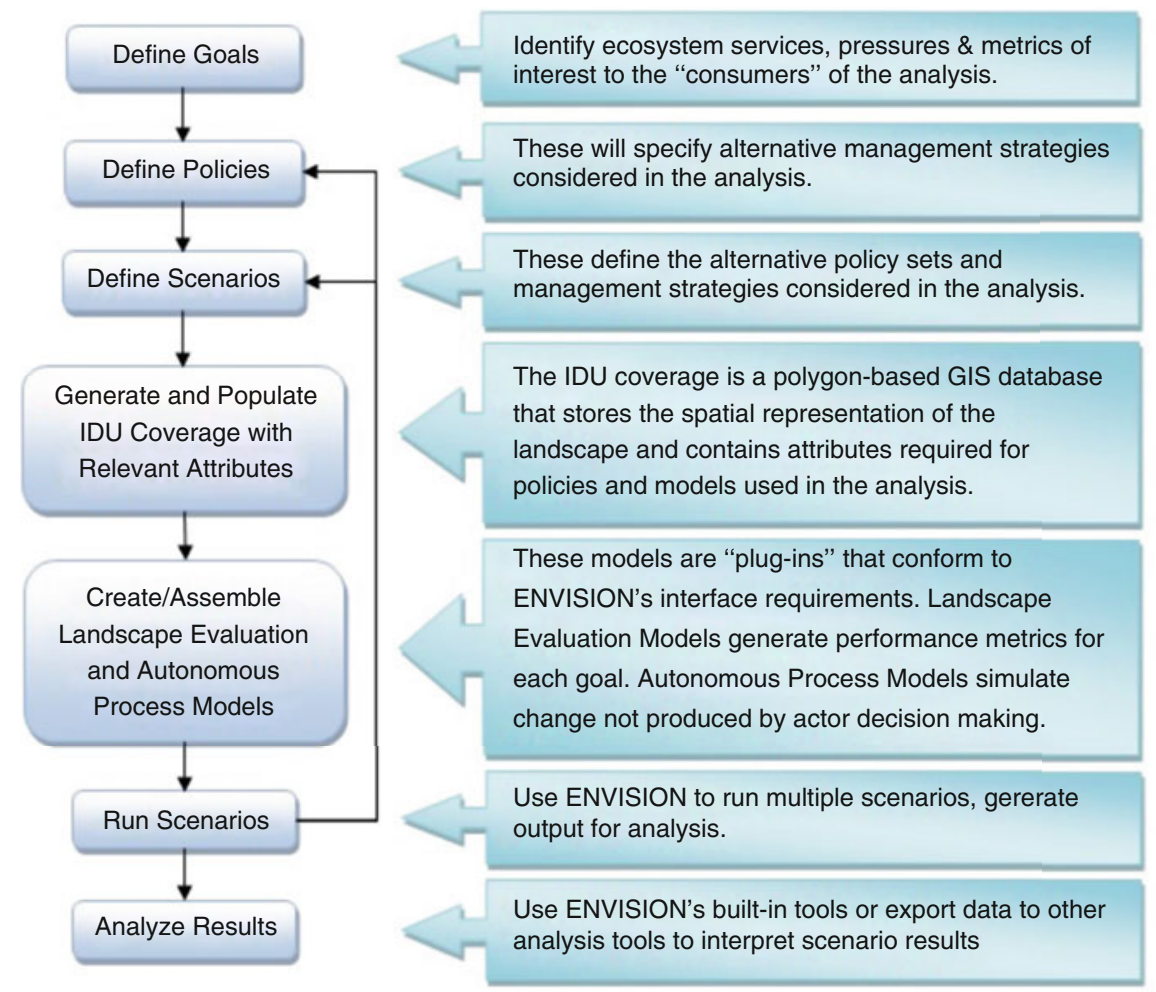

Fig. 2 Workflow for setting up ENVISION applications such as the ENVISION Willamette case study. "IDU" stands for Integrated Decision Unit, the user-defined landscape spatial unit. (Reproduced from http://envision.bioe.orst.edu/)

Modeled scenario results were evaluated, and iterative improvements were made, as necessary, to the workflow outlined in Fig. 2.

The resulting ENVISION Willamette application is a whole watershed model. Through its integration of various plug-in models, it attempts to represent the significant processes related to the supply and fate of water in the entire basin. These processes are both natural (e.g. precipitation, snow dynamics, infiltration, runoff, evapotranspiration) and human (e.g., reservoir operations, irrigation, municipal water use, crop choice). Application drivers include projections of climate, population, land use and income. The integrated ENVISION framework (Fig. 1) operates by simulating the processes across the entire basin per timestep-daily for some processes, annual for others (https://inr.oregonstate.edu/ww2100/analysistopic/future-climate).

Key findings of the ENVISION Willamette Water 2100 case study address longterm (2010-2100) effects of an array of water regulations, land use alternatives, and climate and population scenarios on water scarcity, access to water, and associated ecological, economic and social tradeoffs. 
A detailed summary of findings can be found on the ENVISION website (https:// inr.oregonstate.edu/ww2100/key-findings) including several dozen peer-reviewed journal articles.

Briefly, ENVISION Willamette simulations broke out potential impacts for uplands (primarily forest) and lowlands (primarily urban and agricultural) during the twenty-first century. For example, upland snowpack is predicted to decline by $74-94 \%$ by 2100 , limiting the region's main source of drinking water in summer, and contributing to as much as a ninefold areal increase in forest wildfires that, in turn, will reduce timber revenues and critical fish and wildlife habitat. In the lowlands, growing urban populations are predicted to increase water demand by up to $88 \%$. ENVISION simulations also highlight water management implications and potential strategies for adapting to these complex and interconnected challenges.

\section{ENVISION Plug-in Models}

\subsection{Existing ENVISION Plug-ins}

This section reviews existing ENVISION plug-in models and their applications for the ENVISION Willamette project. In general terms, a plug-in is a software component that adds a specific feature to an existing software application, thereby increasing its functionality. Among the most familiar plug-ins are the innumerable "apps" that can be integrated into the operating systems of cellular phones to expand their functionality. Plug-ins can be very simple or quite complex depending on requirements.

ENVISION is distributed with a number of "standard" plug-ins (Table 1) that can be easily modified for specific applications. These are not required for ENVISION applications, but they have provided significant, commonly used functionality for many ENVISION applications.

Because of the complexity of the ENVISION Willamette application, a set of specialized plug-in models was also developed to achieve the project's hydrologic, ecological and socioeconomic goals. Examples include (1) water system models for simulating stream flow and temperature, and reservoir water management for the basin's stream/river network; (2) ecosystem response models for simulating effects of forestry, agriculture, fire and other disturbances on vegetation dynamics and stream habitat and fish populations; and (3) socioeconomic models for simulating changes in demand for drinking water and irrigation, and changes in land use, regulations, incentives and practices for managing rural and urban lands.

Additional details on ENVISION's standard and Willamette-specific plug-ins can be found in the ENVISION Developers Guide (http://envision.bioe.orst.edu/Down loads.aspx). The integration of these plug-in models within ENVISION provided a means for representing the complex feedbacks needed for estimating tradeoffs among ecological, economic and social processes and outcomes of concern to Willamette River Basin stakeholders. Characterization of such complex tradeoffs 
Table 1 Standard ENVISION plug-ins

\begin{tabular}{l|l}
\hline Plug-in name & Description \\
\hline DynamicVeg & $\begin{array}{l}\text { A sophisticated state transition model for vegetation in response to harvest, } \\
\text { fire and other disturbances. }\end{array}$ \\
\hline FLOW & $\begin{array}{l}\text { Configurable hydrologic model representing water storage and movement } \\
\text { within a landscape of user-defined polygons or a grid. }\end{array}$ \\
\hline Reservoirs & $\begin{array}{l}\text { Submodel of FLOW for defining individual reservoirs and their operations } \\
\text { for holding and releasing water within a stream network. }\end{array}$ \\
\hline WaterMaster & $\begin{array}{l}\text { Submodel of FLOW that utilizes spatially explicit place-of-use, and point- } \\
\text { of-diversion input data to simulate water right diversions as governed by a } \\
\text { prior appropriated water-right system. }\end{array}$ \\
\hline ModFlowAP & Implements the MODFLOW groundwater model. \\
\hline ProgramEvaluator & $\begin{array}{l}\text { Allows users to define evaluative models for specified autonomous pro- } \\
\text { cesses, including biophysical processes such as food and fiber production, } \\
\text { water yield, etc. } \\
\text { instance, a community may want to preserve a certain percentage of the } \\
\text { landscape in agricultural uses, or ensure some level of available buildable } \\
\text { lands, or some other similar landscape statistic. }\end{array}$ \\
\hline Trigger & $\begin{array}{l}\text { Allows changes in one location to dynamically propagate changes into } \\
\text { another location, once a specified threshold condition is met. For example, if } \\
\text { a certain water quality regulatory threshold (TMDL) is exceeded at a given } \\
\text { location, a remediation action such as implementation of riparian buffers can } \\
\text { be triggered. }\end{array}$ \\
\hline QuickFire & $\begin{array}{l}\text { Used for defining how processes (harvest, fire, fertilization...) are allocated } \\
\text { spatially across the landscape to meet defined targets. }\end{array}$ \\
\hline FpatialAllocator & $\begin{array}{l}\text { Sophisticated fire behavior mapping and analysis program that computes } \\
\text { potential fire behavior characteristics (spread rate, flame length, fire line } \\
\text { intensity, etc.). }\end{array}$ \\
\hline Simple fire model. \\
\hline $\begin{array}{l}\text { Specifies a landscape variable whose total value across the landscape is } \\
\text { represented as a trajectory. }\end{array}$ \\
\hline FlammaP
\end{tabular}

within this human-natural system would not have been possible using the same or similar array of models applied in stand-alone mode.

\subsection{Development of New ENVISION Plug-ins-VELMA Example}

The list of ENVISION plug-ins is evolving as the framework is applied to new places and questions. In this section we provide an example of the general process by which an existing spatial model can be developed as a plug-in to extend ENVISION's capabilities for integrated EBM planning.

One of ENVISION's most pressing needs is a scalable, process-based biogeochemical model capable of addressing local and regional water quality and 


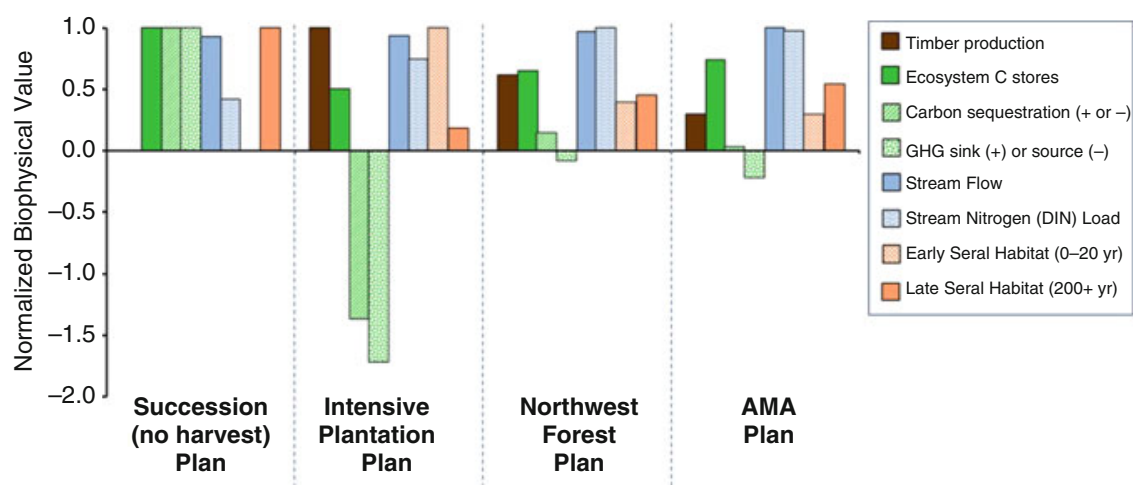

Fig. 3 VELMA results showing predicted ecosystem services and tradeoffs in the year 2200 when four alternative forest management scenarios (Cissel et al. 1999) were applied to present-day landscape conditions in the $230 \mathrm{~km}^{2}$ Blue River watershed in Oregon. For each target ecosystem service - timber production, etc. (see legend) — simulated biophysical outputs (y-axis) across all four management scenarios are normalized with respect to the greatest simulated value for that ecosystem service. For example, timber production was at maximum for the Intensive Plantation Plan ( $\mathrm{y}$-axis value $=1.0$ ), zero for the Succession plan (y-axis value $=0$ ), and 62 and $30 \%$ of maximum, respectively, for the Northwest Forest Plan (NWFP) and the Adaptive Management Plan (AMA)

ecosystem services trade-off concerns. This gap could most easily be addressed by integrating a generalized landscape biogeochemical model plug-in with ENVISION's existing hydrologic FLOW plug-in (Table 1).

We chose the Visualizing Ecosystem Land Management Assessment (VELMA) model for this purpose. Developed by the EPA and Georgia Institute of Technology, VELMA is a spatially distributed, eco-hydrological model that links a land-surface hydrology model with a terrestrial biogeochemistry model for simulating the integrated responses of vegetation, soil, and water quality and quantity to interacting stressors. VELMA is applicable to essentially any terrestrial ecosystem (urban, agricultural, forest, grassland, prairie, wetland, etc.), as well as to mixed-use watersheds and regional basins (Abdelnour et al. 2011, 2013; McKane et al. 2014a, b; Hoghooghi et al. 2018; McKane et al. 2018a, b, c).

VELMA simulates how climate, land use, land cover and natural and engineered landscape features control the fate and transport of water, nutrients and toxics in watersheds, across scales ranging from small plots to large river basins, and from days to centuries. In addition to water quality assessments, VELMA has also been used to simulate climate and land use impacts on the capacity of ecosystems to provide a variety of ecosystem goods and services vital to human health and wellbeing - clean drinking water, flood prevention, food and fiber production, carbon sequestration, habitat for fish and wildlife, and others (e.g., Fig. 3). 


\subsection{Developing the ENVISION VELMA Plug-in}

Using plug-in development procedures outlined on the ENVISION website (http:// envision.bioe.orst.edu/Guides/CreatingPlugins.aspx), we developed a plug-in for VELMA's biogeochemical model, disconnected from VELMA's hydrologic model, and programmed to work interactively with ENVISION's existing hydrologic FLOW plug-in. FLOW provides many of the same functions as VELMA's hydrologic model, e.g., water infiltration, lateral surface and subsurface flow, stream routing, and evapotranspiration. Importantly, FLOW has the major advantage of being integrated with existing ENVISION plug-ins for informing management of the Willamette River basin's water, ecosystem and socioeconomic systems.

Figure 4 schematically illustrates the bidirectional exchange of information between the FLOW and VELMA biogeochemical plug-ins and, potentially, with ENVISION's standard plug-ins. All plug-ins are housed in a shared ENVISION library on disk. This library also contains plug-in input parameters (XML), environmental drivers (csv), spatial data (asc), and a project file (envx) that ENVISION uses to initialize a particular application.

The Flow XML file (HBV.xml in Fig. 4) describes a set of methods in the shared library that will be executed as part of the FLOW plug-in for each time step in the ENVISION application. The methods include (1) a hydrologic method that works on a specified landscape grid; (2) a built-in evapotranspiration method; and (3) the VELMA plug-in that is also placed in the shared library.

The VELMA plug-in is initialized using another XML file containing code that signals when the plug-in will be called, in this case at the beginning of each daily time step.

For testing purposes, a "BlueRiver_VelmaPlugin.xml" file was created and applied to demonstrate that ENVISION calls the VELMA plug-in, successfully engaging VELMA's biogeochemical model for the Blue River project application described above.

\section{Potential Additional ENVISION Plug-ins for Coastal Ecosystem Applications}

To further explore how ENVISION could be extended for EBM assessments, we compiled a list of existing and potential model plugins (Table 2) that are in current use by EPA and other researchers engaged in coastal ecosystem recovery planning.

Table 2 reflects our interest in the integration of models that have been or could be integrated for informing ongoing restoration activities across the EPA's National Estuary Program (NEP) (https://www.epa.gov/nep/local-estuary-programs). Many of these models have already been developed as ENVISION plug-ins for EBM projects at a number of NEP sites-Guánica Bay, Puerto Rico; Tampa Bay, Florida; and Puget Sound, Washington. Applications at these sites aim to assist community 


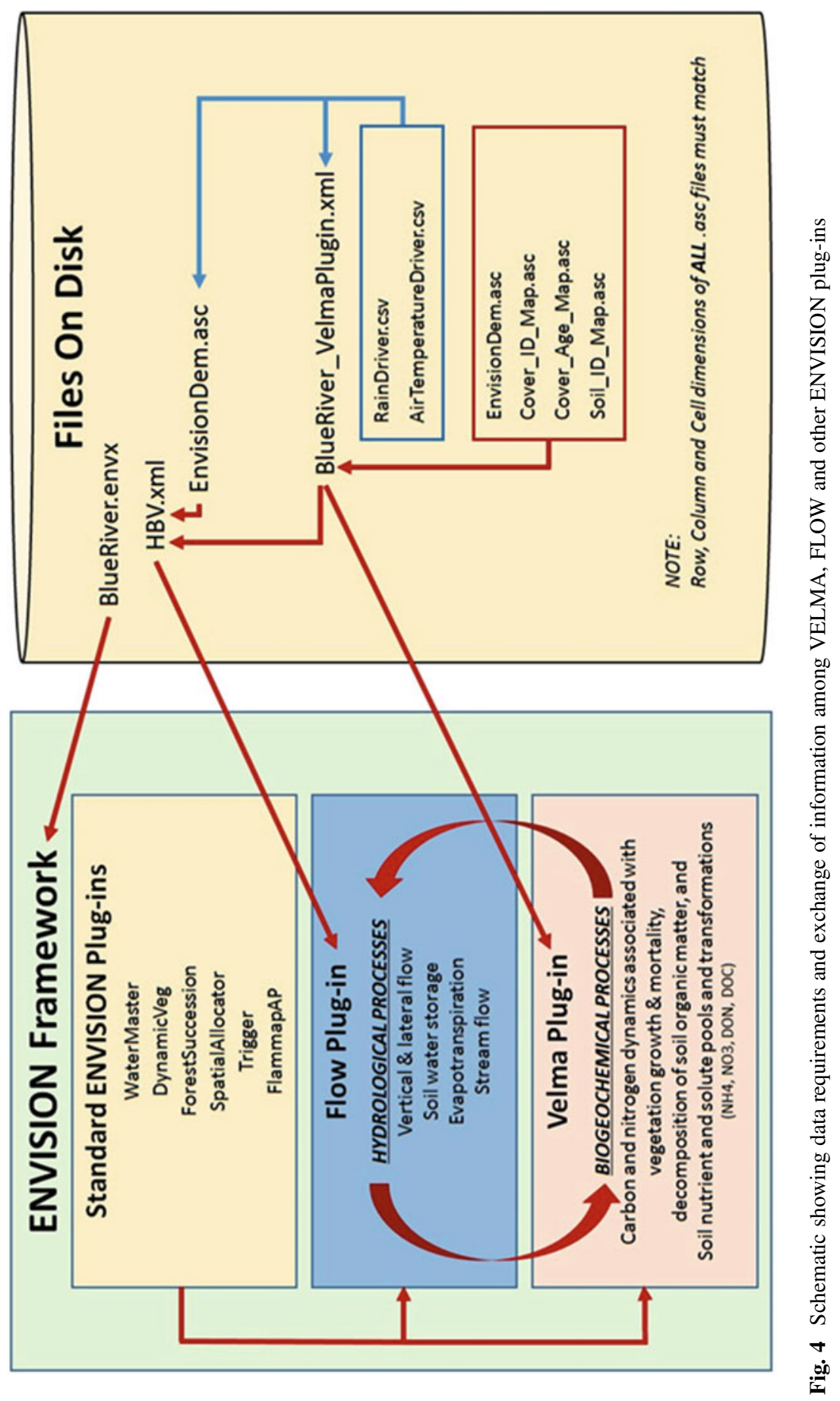




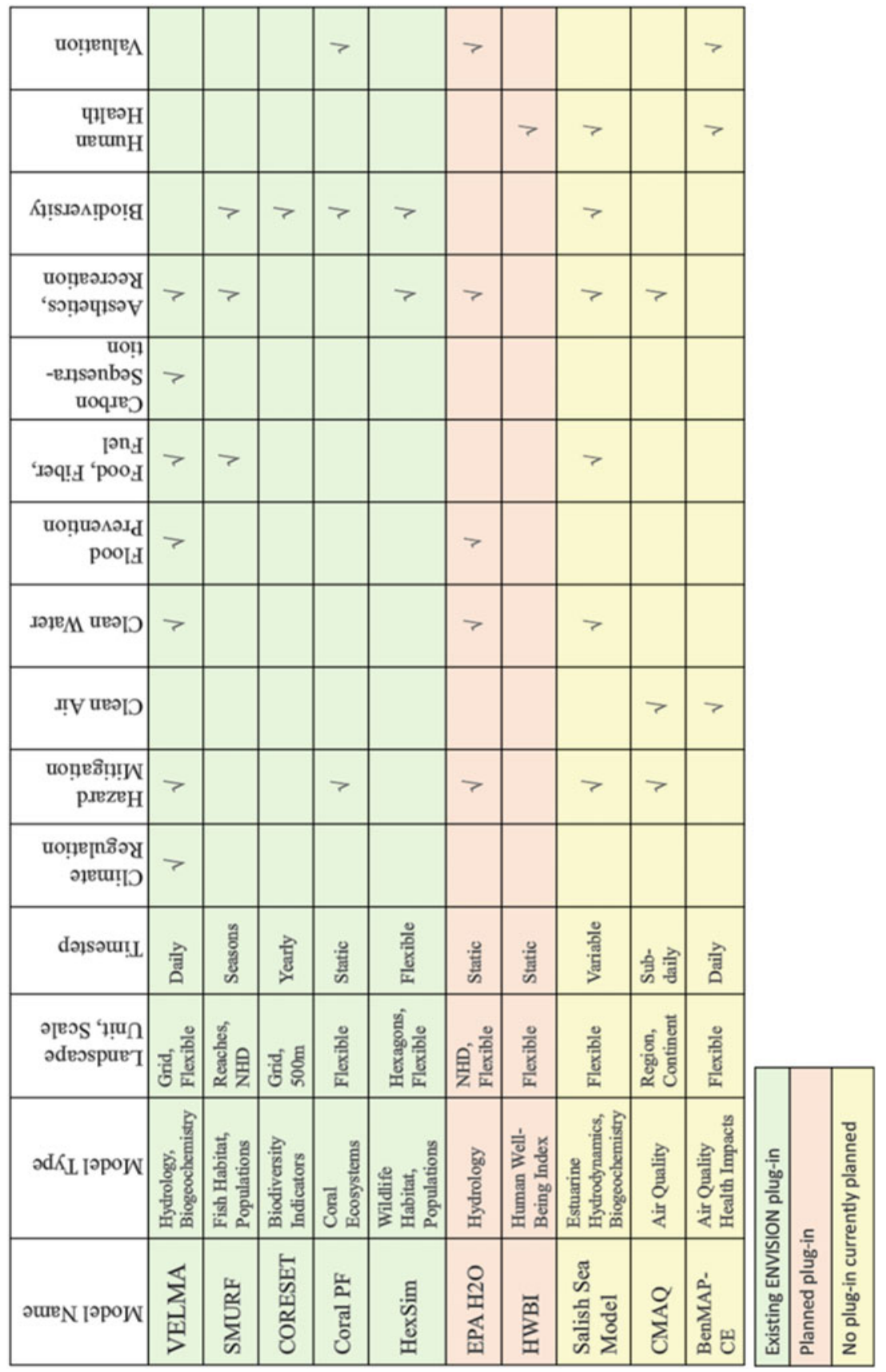

충웜

ํㅡ윻ำ

혀웡

苍宁

氙芯

苍瓷

के

융휴

उ $=$ ह

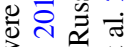

उं

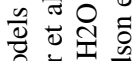

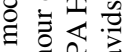

过这苛

匈造突

造造完

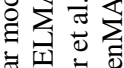

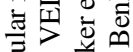

氖苍芯

류 증

के 过

可

응 논

宫番

8 过

沙要

ฝึ ฟ

ᄒ

ญี

䓀 $\infty$

융

尙

든 웡

을 글

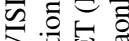

艺武

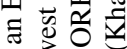

可嵒

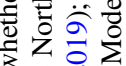

บ ำ

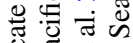

ㅎำ

㱐

흥 苍芒 证 


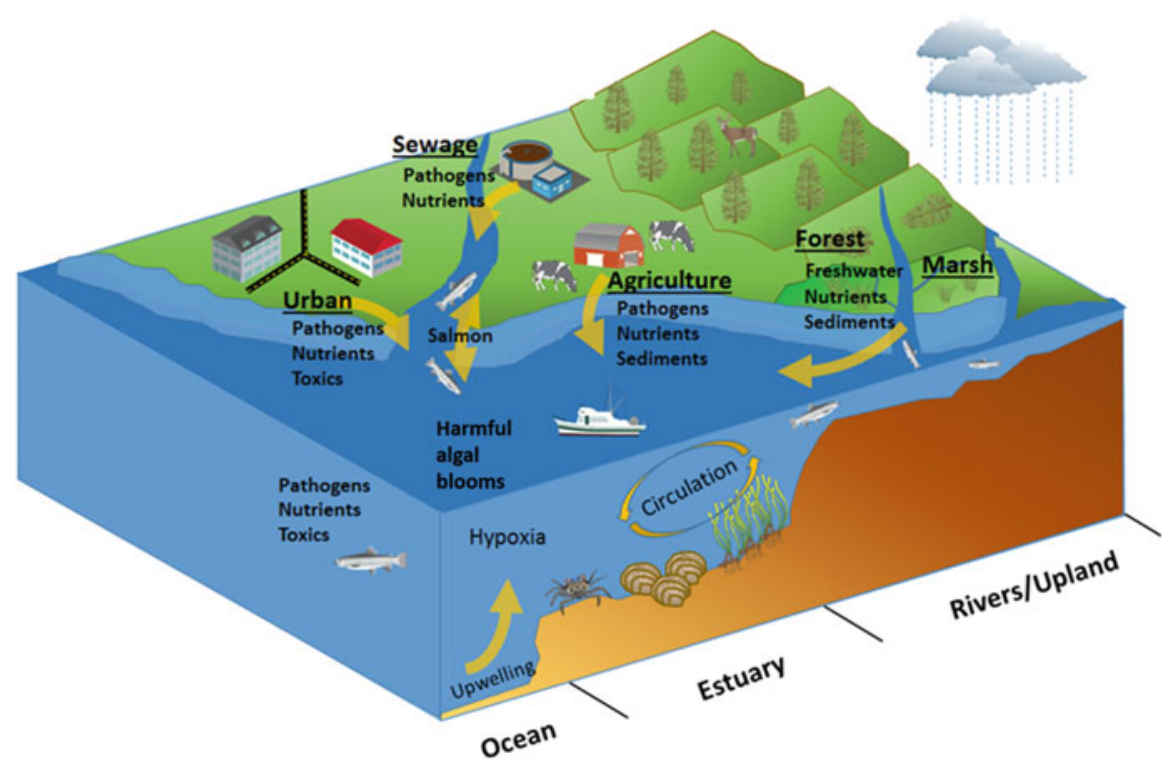

Fig. 5 Generalized representation of major terrestrial pollutant sources and transfers to marine waters in populated coastal ecosystems. Image: Darryl Marois

decision makers in balancing ecological, economic and social criteria over timescales relevant to immediate needs and long-term planning goals.

A major challenge in modeling coastal ecosystems is the establishment of a coupled human-natural modeling framework capable of addressing transfers of terrestrial nutrients and toxic chemicals to marine waters, and consequent impacts on marine life and ecosystem goods and services. Figure 5 schematically summarizes typical coastal terrestrial-to-marine pollutant transfers, highlighting some major challenges for modeling EBM of NEP sites, such as Puget Sound's 31,000 $\mathrm{km}^{2}$ basin and its mosaic of terrestrial, marine and human environments.

Characterizing such transfers and impacts is critical to estuarine restoration efforts in densely populated coastal areas. For example, in the Puget Sound National Estuary, killer whales (orcas) and their prey, Chinook salmon, have accumulated dangerously high levels of organic chemicals such as PCBs, PBDEs and PAHs (https://ecology.wa.gov/Water-Shorelines/Puget-Sound/Orca-task-force). This wellpublicized situation has made these endangered species iconic indicators of the rapidly declining condition of Puget Sound's estuarine food web, perhaps foreshadowing a system-wide collapse such as those observed in Chesapeake Bay and other estuaries globally (Gelfenbaum et al. 2006).

We developed the ENVISION VELMA plug-in to better simulate EBM strategies for reducing transfers of terrestrial nutrients and contaminants to estuarine ecosystems in general, and to Puget Sound ongoing case studies in particular. Both ENVISION and VELMA have been extensively but separately applied to the 
terrestrial portion of the Puget Sound basin (e.g., Bolte and Vache 2010 for ENVISION; McKane et al. 2018a, b, c for VELMA). With VELMA's capabilities for estimating effects of land use and other disturbances on water quality, we anticipate that the ENVISION VELMA plug-in, when integrated with existing and proposed ENVISION plug-ins (Tables 1 and 2), can effectively extend ENVISION's functionality for addressing terrestrial and marine water quality and ecosystem service objectives pertinent to coastal ecosystem EBM goals. The State of Washington's Puget Sound Partnership has formalized such goals in terms of $\sim 25$ terrestrial-marine Vital Signs (ecosystem services), each monitored and managed under a specific Implementation Strategy (https://www.eopugetsound.org/articles/puget-sound-vitalsigns-0).

Figure 6 conceptually illustrates ENVISION's flexibility for integrating existing and proposed plug-ins for coastal ecosystem EBM projects such as Puget Sound. This example includes a structured decision-making workflow involving development and application of stakeholder-relevant policies and decision scenarios, ecological production functions, ecosystem goods and services production functions, and benefit functions. The intent of such integration is to enable analyses of how alternative EBM options impact tradeoffs among ecological, socioeconomic and human health endpoints of concern to stakeholders.

In collaboration with Puget Sound community, tribal, state and federal partners, we have initiated development of such a human-natural systems framework, inclusive of coastal terrestrial-marine-human system interactions. This effort would merge the following:

- Existing Oregon State University ENVISION Puget Sound applications (Bolte and Vache 2010; http://envision.bioe.orst.edu/StudyAreas/PugetSound/).

- Ongoing EPA Puget Sound applications of VELMA (McKane et al. 2018a, b, c)

- Pacific Northwest National Laboratory applications of the Salish Sea Model (SSM) (Khangaonkar et al. 2018, 2019), coupled with National Oceanic and Atmospheric Administration applications of the Atlantis model (Levin et al. 2009), for simulating the circulation and fate of terrestrial pollutant inputs within the Puget Sound marine ecosystem and consequent impacts on water quality, fisheries and threatened food web species.

- Existing and new ENVISION plug-ins developed by EPA and others for extending ENVISION's applicability to coastal ecosystems (Tables 1 and 2).

Besides specific case study objectives, the overarching intent of these activities is to establish a generally applicable, coupled human-natural modeling framework that coastal ecosystem community stakeholders and restoration planners can use to anticipate and visualize how effects of EBM options in any particular location can propagate downstream and downcurrent with far-reaching benefits and tradeoffs for terrestrial and marine ecosystem services. 


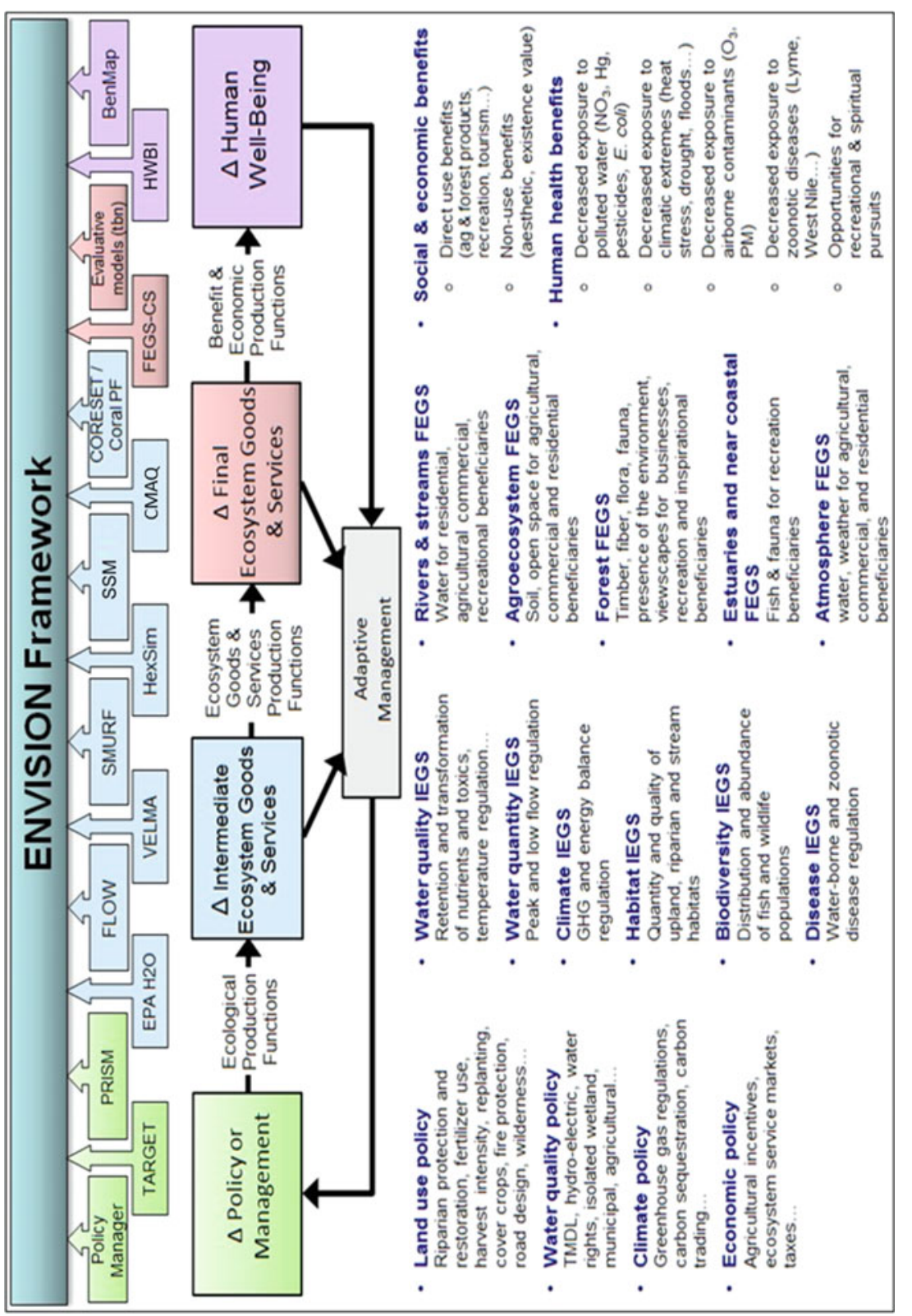

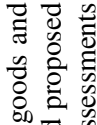

政

क्ष

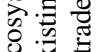

ช

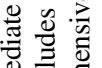

过

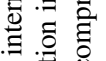

ธี

들

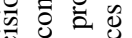

융 专

证

를

类

चี

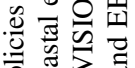

。

च

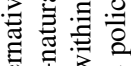

ฮี ส․

능

을

过

o bo

웡

on

क

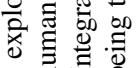

로잉

흘

ธำ

ปี

50.

के 두

z ज च

ज्ञ

之o

记

สำ

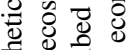

氞㤩总

\&ै $\Xi \frac{1}{0}$

분 


\section{Addressing Uncertainty Propagation within Multi-Model Frameworks}

ENVISION and other multi-model decision support frameworks (Lewis et al. 2020) have emerged as important tools for informing EBM. A common concern about such frameworks is that uncertainties in one model can propagate and magnify as information gets passed from one model to the next, putting into question a framework's final outputs. Uncertainties in outputs can originate from uncertainties in input data that include measurement and processing errors; in individual models that include conceptual, mathematical, and computational errors; and in model-to-model incompatibilities such as differences in spatial and temporal scales that can propagate errors.

To reduce these sources of uncertainty, ENVISION employs a Monte-Carlo simulation approach that uses statistical descriptors of decision processes and, optionally, scenario-specific statistical descriptors of model inputs. This approach allows a given scenario to be run multiple times to produce a probabilistic distribution of possible outcomes (Bolte et al. 2012).

This uncertainty-based approach has additional advantages. For example, it is well-suited to the explore-then-test paradigm routinely emphasized in ENVISION applications to more effectively engage stakeholders in the design and analysis of alternative future scenarios (http://envision.bioe.orst.edu/CaseStudies.aspx). This approach also facilitates assessments of landscape vulnerability-the predisposition of a system to be adversely affected by stressors and lacking in capacity to adapt to environmental change (Bolte et al. 2012; IPCC 2014). And, when coupled with a multi-criteria assessment procedure (Hajkowicz and Collins 2007; Kiker et al. 2005), this approach can be used to estimate stakeholder weighting-of-importance for various ecosystem services.

\section{Summary and Conclusions}

This chapter has summarized key elements of the ENVISION decision support framework and how it has been used to help a wide range of communities develop and apply alternative decision scenarios in support of EBM planning. We used the ENVISION Willamette case study in Oregon to highlight key ENVISION features for this purpose. These include a dynamic GIS engine for representing changing landscape characteristics; a multi-agent framework for representing different decision makers; a rich representation of policies limiting decision maker's options; and an extensible array of model plug-ins for simulating ecological, economic and social tradeoffs in response to alternative future scenarios.

Using EPA's VELMA biogeochemical model, we demonstrated the relative ease of developing ENVISION plug-ins for enhancing water quality and ecosystem 
service assessments. We also demonstrated a hypothetical example and recommendations for developing additional model plug-ins to extend ENVISION's capabilities for integrated EBM planning in coastal ecosystems. This demonstration focused on our ongoing case studies in Puget Sound and other National Estuaries experiencing increasing terrestrial pollutant loads and consequent impacts on marine ecosystem goods and services.

Many of the recommended plug-ins already exist for extending ENVISION to simulate coastal terrestrial-marine interactions. The integration and application of these plug-ins via ENVISION would represent an important step in helping restoration planners and managers identify terrestrial pollutant sources and best practices for reducing terrestrial loadings to the marine ecosystem.

In conclusion, depending upon the scope of EBM questions and objectives, ENVISION and other coupled human-natural modeling frameworks (chapter "Projecting Changes to Coastal and Estuarine Ecosystem Goods and Services: Models and Tools") can require a substantial and expensive effort, potentially involving local, state, federal and academic organizations working in concert to assess how alternative decision scenarios may impact the capacity of local and regional ecosystems to sustainably provide vital ecosystem services.

That said, an argument can be made that the development and application of coupled natural-human modeling frameworks are a cost-effective means for discovering and guiding the implementation of EBM solutions to "wicked" ecologicaleconomic-social problems. That is, problems that are "difficult or impossible to solve for as many as four reasons: incomplete or contradictory knowledge, the number of people and opinions involved, the large economic burden, and the interconnected nature of these problems with other problems" (Kolko 2012).

Obviously, no model can completely address these difficulties, but the integrative and analytical advantages of EBM frameworks such as ENVISION can at least provide informed and useful approximations based on best available data and science.

Acknowledgements The information in this document has been funded in part by the U.S. Environmental Protection Agency (U.S. EPA). It has been subjected to the Agency's peer and administrative review, and it has been approved for publication as an EPA document. We thank Rich Fulford, Tim O'Higgins, Ted DeWitt, Matt Harwell and Chloe Jackson for review comments on earlier manuscript versions.

\section{References}

Abdelnour, A., Stieglitz, M., Pan, F., \& McKane, R. (2011). Catchment hydrological responses to forest harvest amount and spatial pattern. Water Resources Research, 47, W09521. https://doi. org/10.1029/2010WR010165 
Abdelnour, A., McKane, R., Stieglitz, M., Pan, F., \& Cheng, Y. (2013). Effects of harvest on carbon and nitrogen dynamics in a Pacific Northwest forest catchment. Water Resources Research, 49 (3), 1292-1313.

Berman, J. D., Fann, N., Hollingsworth, J. W., Pinkerton, K. E., Rom, W. N., Szema, A. M., Breysse, P. N., White, R. H., \& Curriero, F. C. (2012). Health benefits from large-scale ozone reduction in the United States. Environmental Health Perspectives, 120(10), 1404-1410.

Bolte, J., \& Vache, K. (2010). Envisioning Puget Sound alternative futures: PSNERP final report. Washington State Department of Fish and Wildlife.

Bolte, J., McKane, R., Phillips, D., Schumaker, N., White, D., Brookes, A., \& Olszyk, D. (2011). In Oregon, the EPA calculates nature's worth now and in the future. Solutions, 2(6), 35-41.

Bolte, J., McKane, R., Phillips, D., Schumaker, N., White, D., Brookes, A., Olszyk, D., Burdick, C., \& Papenfus, M. (2012). An extensible decision support system for evaluating ecosystem services under alternative future scenarios-A Willamette River Basin case study. Clearance Number ORD-002136. Washington, DC: U.S. Environmental Protection Agency.

Bradley, M. P., Fisher, W., Dyson, B., Yee, S., Carriger, J., Gambirazzio, G., Bousquin, J., \& Huertas, E. (2016). Application of a structured decision process for informing watershed management options in Guánica Bay, Puerto Rico. National Health and Environmental Effects Research Laboratory, Office of Research and Development, US Environmental Protection Agency.

Cissel, J., Swanson, F., District, B. R. R., \& Leader, E. T. (1999). Blue River Landscape Study: Testing an alternative approach. Unpublished paper. Blue River Ranger District, Blue River, Oregon, 97413.

Davidson, K., Hallberg, A., McCubbin, D., \& Hubbell, B. (2007). Analysis of PM2. 5 using the environmental Benefits Mapping and Analysis Program (BenMAP). Journal of Toxicology and Environmental Health, Part A, 70(3-4), 332-346.

Gelfenbaum, G., Mumford, T., Brennan, J., Case, H., Dethier, M., Fresh, K., Goetz, F., van Heeswijk, M., Leschine, T. M., \& Logsdon, M. (2006). Coastal habitats in Puget Sound: A research plan in support of the Puget Sound Nearshore Partnership (No. TR-2006-1). Seattle, WA: Corps of Engineers.

Hajkowicz, S., \& Collins, K. (2007). A review of multiple criteria analysis for water resource planning and management. Water Resources Management, 21(9), 1553-1566.

Hoghooghi, N., Golden, H., Bledsoe, B., Barnhart, B., Brookes, A., Djang, K., Halama, J., McKane, R., Nietch, C., \& Pettus, P. (2018). Cumulative effects of low impact development on watershed hydrology in a mixed land-cover system. Water, 10(8), 991.

IPCC. (2014). Climate Change 2014: Impacts, adaptation and vulnerability. In Contribution of Working Group II to the Fifth Assessment Report of the Intergovernmental Panel on Climate Change (Vol. 1, p. 32). New York: Cambridge University Press.

Jaeger, W. K., Amos, A., Bigelow, D. P., Chang, H., Conklin, D. R., Haggerty, R., Langpap, C., Moore, K., Mote, P. W., Nolin, A. W., \& Plantinga, A. J. (2017). Finding water scarcity amid abundance using human-natural system models. Proceedings of the National Academy of Sciences, 114(45), 11884-11889.

Khangaonkar, T., Nugraha, A., Xu, W., Long, W., Bianucci, L., Ahmed, A., Mohamedali, T., \& Pelletier, G. (2018). Analysis of hypoxia and sensitivity to nutrient pollution in Salish Sea. Journal of Geophysical Research-Oceans, 123(7), 4735-4761.

Khangaonkar, T., Nugraha, A., Xu, W., \& Balaguru, K. (2019). Salish Sea response to global climate change, sea level rise, and future nutrient loads. Journal of Geophysical ResearchOceans, 124(6), 3876-3904.

Kiker, G. A., Bridges, T. S., Varghese, A., Seager, T. P., \& Linkov, I. (2005). Application of multicriteria decision analysis in environmental decision making. Integrated Environmental Assessment and Management: An International Journal, 1(2), 95-108.

Kolko, J. (2012). Wicked problems: Problems worth solving: A handbook \& a call to action. Austin, TX: AC4D. 
Levin, P. S., Fogarty, M. J., Murawski, S. A., \& Fluharty, D. (2009). Integrated ecosystem assessments: Developing the scientific basis for ecosystem-based management of the ocean. PLoS Biology, 7(1).

Lewis, N. S., Marois, D. E., Littles, C. J., \& Fulford, R. S. (2020). Projecting changes to coastal and estuarine ecosystem goods and services - models and tools. In T. O'Higgins, M. Lago, \& T. H. DeWitt (Eds.), Ecosystem-based management, ecosystem services and aquatic biodiversity: Theory, tools and applications (pp. 235-254). Amsterdam: Springer.

Luecken, D. J., Yarwood, G., \& Hutzell, W. T. (2019). Multipollutant modeling of ozone, reactive nitrogen and HAPs across the continental US with CMAQ-CB6. Atmospheric Environment, 201, 62-72.

McKane, R. B., Brookes, A., Djang, K., Papenfus, M., Ebersole, J., Phillips, D., Halama, J., Pettus, P., Burdick, C., \& Russell, M. (2014a). Sustainable and healthy communities Pacific Northwest demonstration study. Report No. ORD-007386 of the U.S. Environmental Protection Agency. Washington, DC.

McKane, R. B., Brookes, A., Djang, K., Stieglitz, M., Abdelnour, A., \& Pan, F. (2014b). Enhanced version of VELMA ecohydrological modeling and decision support framework to address engineered and natural applications of GI for reducing nonpoint inputs of nutrients, contaminants, and sediments. Report No. ORD-010080 of the U.S. Environmental Protection Agency. Washington, DC.

McKane, R. B., Barnhart, B., Pettus, P., Halama, J., Brookes, A., Djang, K., Khangaonkar, T., Harvey, C., Kaplan, I., Luna, H., Schmidt, M., Howe, E., \& Levin, P. (2018a). An integrated environmental and human systems modeling framework for Puget Sound restoration planning. Salish Sea Ecosystem Conference, Seattle, Washington.

McKane, R. B., Barnhart, B., Pettus, P., Halama, J., Brookes, A., Djang, K., Khangoankar, T., Kaplan, I., Harvey, C., Morzaria Luna, H., Schmidt, M., Howe, E., Levin, P., Francis, T., Baker, J., Stanley, S., \& Hume, C. (2018b). A science-governance partnership for integrating ecosystem services into Puget Sound restoration planning. ACES 2018 Conference Proceedings, Washington, DC.

McKane, R. B., Halama, J., Pettus, P., Barnhart, B., Brookes, A., Djang, K., Blair, G., Hall, J., Kane, J., Swedeen, P., \& Benson, L. (2018c). How Visualizing Ecosystem Land Management Assessments (VELMA) modeling quantifies co-benefits and tradeoffs in Community Forest management. Keynote presentation to the Northwest Community Forest Forum, Astoria, OR, May 10-11, 2018.

Melbourne-Thomas, J., Johnson, C. R., Fung, T., Seymour, R. M., Chérubin, L. M., AriasGonzález, J. E., et al. (2011a). Regional-scale scenario modeling for coral reefs: A decision support tool to inform management of a complex system. Ecological Applications, 21, 1380-1398. https://doi.org/10.1890/09-1564.

Melbourne-Thomas, J., Johnson, C. R., Perez, P., Eustache, J., Fulton, E. A., \& Cleland, D. (2011b). Coupling biophysical and socioeconomic models for coral reef systems in Quintana Roo, Mexican Caribbean. Ecology and Society, 16, 23.

Orlando, J., Yee, S., Harwell, L., \& Smith, L. (2017). Technical guidance for constructing a Human Well-Being Index (HWBI): A Puerto Rico example. U.S. Environmental Protection Agency Report No. EPA/600/R-16/363.

Russell, M., Harvey, J., Ranade, P., \& Murphy, K. (2015). EPA H2O user manual. EPA/600/R-15/ 090. Washington, DC: US EPA Office of Research and Development.

Santelmann, M., McDonnell, J., Bolte, J., Chan, S., Morzillo, A. T., \& Hulse, D. (2012). Willamette water 2100: River basins as complex social-ecological systems. WIT Transactions on Ecology and the Environment, 155, 575-586.

Schumaker, N. H., Brookes, A., Dunk, J. R., Woodbridge, B., Heinrichs, J. A., Lawler, J. J., Carroll, C., \& LaPlante, D. (2014). Mapping sources, sinks, and connectivity using a simulation model of northern spotted owls. Landscape Ecology, 29(4), 579-592.

Snyder, M. N., Schumaker, N. H., Ebersole, J. L., Dunham, J. B., Comeleo, R. L., Keefer, M. L., Leinenbach, P., Brookes, A., Cope, B., Wu, J., \& Palmer, J. (2019). Individual based modeling 
of fish migration in a 2-D river system: Model description and case study. Landscape Ecology, 34(4), 737-754.

Spies, T. A., White, E. M., Kline, J. D., Fischer, A. P., Ager, A., Bailey, J., Bolte, J., Koch, J., Platt, E., Olsen, C. S., \& Jacobs, D. (2014). Examining fire-prone forest landscapes as coupled human and natural systems. Ecology and Society, 19(3), 9.

Villarreal, M. L., Labiosa, B., \& Aiello, D. (2017). Evaluating land-use change scenarios for the Puget Sound Basin, Washington, within the ecosystem recovery target model-based framework (No. 2017-1057). US Geological Survey.

Open Access This chapter is licensed under the terms of the Creative Commons Attribution 4.0 International License (http://creativecommons.org/licenses/by/4.0/), which permits use, sharing, adaptation, distribution and reproduction in any medium or format, as long as you give appropriate credit to the original author(s) and the source, provide a link to the Creative Commons licence and indicate if changes were made.

The images or other third party material in this chapter are included in the chapter's Creative Commons licence, unless indicated otherwise in a credit line to the material. If material is not included in the chapter's Creative Commons licence and your intended use is not permitted by statutory regulation or exceeds the permitted use, you will need to obtain permission directly from the copyright holder. 